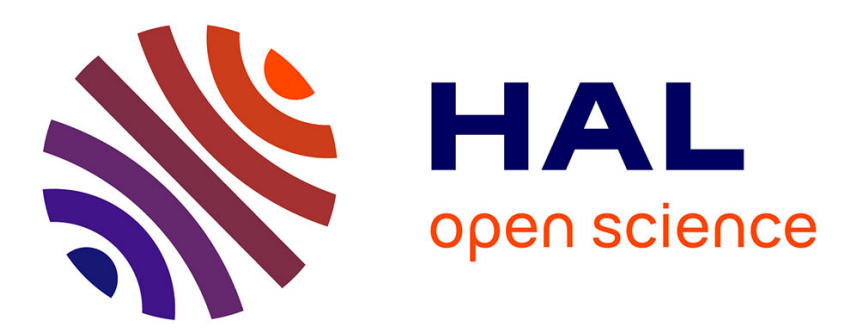

\title{
Electrical conductivity of omphacite and garnet indicates limited deep water recycling by crust subduction
}

Hanyong Liu, Kai Zhang, Jannick Ingrin, Xiaozhi Yang

\section{To cite this version:}

Hanyong Liu, Kai Zhang, Jannick Ingrin, Xiaozhi Yang. Electrical conductivity of omphacite and garnet indicates limited deep water recycling by crust subduction. Earth and Planetary Science Letters, 2021, 559, pp.116784. 10.1016/j.epsl.2021.116784 . hal-03134606

\section{HAL Id: hal-03134606 \\ https://hal.univ-lille.fr/hal-03134606}

Submitted on 8 Feb 2021

HAL is a multi-disciplinary open access archive for the deposit and dissemination of scientific research documents, whether they are published or not. The documents may come from teaching and research institutions in France or abroad, or from public or private research centers.
L'archive ouverte pluridisciplinaire HAL, est destinée au dépôt et à la diffusion de documents scientifiques de niveau recherche, publiés ou non, émanant des établissements d'enseignement et de recherche français ou étrangers, des laboratoires publics ou privés. 

deep water recycling by crust subduction

${ }^{1}$ State Key Laboratory for Mineral Deposits Research, School of Earth Sciences and Engineering, Nanjing University, Nanjing 210023, PR China 


\section{Abstract}

It is usually stated that oceanic crust recycling at subduction zones introduces large quantities of water into Earth's interior. However, it remains clouded how much water is recycled to the deep mantle. This is largely due to the challenge in directly sampling, and analyzing the water content of, a deep subducting crust. The subducting crust below $\sim 30 \mathrm{~km}$ depth is dominated by omphacite and garnet in eclogite-facies rocks. Here we have determined the electrical conductivity of omphacite and garnet in representative subduction-related eclogites, each with varying contents of $\mathrm{Fe}$ and $\mathrm{H}_{2} \mathrm{O}$ that are key in electrical conduction. Considering the measured conductivity, the eclogite chemistry by geochemical investigations and the highly resistive property of subducting crusts by geophysical surveys, we demonstrate that, at 70-120 km depths in the subducting crust, the $\mathrm{H}_{2} \mathrm{O}$ contents of omphacite and garnet are strikingly small, with the maximum value being $<400$ and $<80 \mathrm{ppm}$ in the former and latter, respectively. The very small water contents indicate extremely water-poor conditions, or very low water activity, during the eclogite-facies metamorphism and in the system. This further implies the absence of appreciated amounts of hydrous phases such as amphibole and chlorite in the matrix, because of the strong ability of omphacite and garnet in hosting water as documented in natural samples. We suggest that the recycling of water to the deep mantle by oceanic crust subduction is limited. The results are important for modeling the conductivity of subducting slabs and understanding the deep water circulation.

\section{Introduction}

The transport of water from the hydrosphere to the mantle plays a critical role in affecting mantle dynamics, magma genesis and Earth's habitability. Water is recycled back to the mantle by slab subduction. At very shallow depths (e.g., $<20 \mathrm{~km}$ ), the input 
of water into the mantle is primarily controlled by pore water (Peacock, 1990; Cai et al., 2018). In a downgoing slab at greater depths, however, water chiefly occurs as $\mathrm{OH}$ groups bound in the structure of the constitutive minerals, both hydrous and nominally anhydrous, note that $\mathrm{H}_{2}$ dissolution in minerals is significant only at very high pressure and reducing conditions (Yang et al., 2016). As a slab descends, water is gradually lost by the breakdown of hydrous minerals such as amphibole and chlorite at depths mostly $<100 \mathrm{~km}$, due to their instabilities at high temperature (Peacock, 1990; Liu et al., 1996; Frost, 2006; Schmidt and Poli, 2014). Driven by its low density, the released water rises, metasomatizes wallrocks and causes melting in the wedge. This causes the development and widespread distribution of subduction zone volcanism and ore deposits.

It is widely believed that the crust layer in the slab is important for water recycling, because most of the slab water is initially stored there (Ito et al., 1983; Peacock, 1990; Dixon et al., 2002; Van Keken et al., 2002; Schmidt and Poli, 2014). Beyond 30 km depth, the slab crust is dominated by eclogites (via phase change), consisting mainly of nominally anhydrous omphacite and garnet that are the main water carriers in eclogites after hydrous minerals decompose (Lu and Keppler, 1997; Bromiley and Keppler, 2004; Schmidt and Poli, 2014). As such, the water contents of omphacite and garnet are key to understanding water recycling to the deep mantle. Omphacite and garnet in terrain eclogites, that were once subducted to mantle depths and then returned to surface, could hold up to several thousands of ppm $\mathrm{H}_{2} \mathrm{O}$ as structural $\mathrm{OH}$, leading to the suggestion that the subducting crust is able to carry large quantities of water into the deep mantle beyond the stability of the hydrous phases (Katayama and Nakashima, 2003; Katayama et al., 2006; Sheng et al., 2007). The high water contents of omphacite and garnet in the eclogites may, however, have suffered from complex secondary fluid-rock interactions postdating eclogite peak-metamorphism (e.g., Sheng et al., 2007; Schmädicke and Gose, 
2017). It is thus obscure how much water is present in omphacite and garnet in the deep subducting crust.

The electrical conductivity of nominally anhydrous minerals (NAMs) is sensitive to water (Karato, 1990; Dai and Karato, 2009; Yoshino et al., 2009; Yang et al., 2011, 2012; Yang and McCammon, 2012; Zhang et al., 2012, 2019; Zhao and Yoshino, 2016; Liu et al., 2019). Meanwhile, electromagnetic surveys offer a direct window into Earth's interior. In this context, constraints can be provided on the water contents of omphacite and garnet in the subducting crust (and water recycling), if the conductivity structure of subducting crusts is resolved and the electrical property of subduction-related materials is determined. In a recent work, Liu et al. (2019) have quantified the effect of water on the conductivity of omphacite and garnet, and provided a preliminary constraint on the likely water content in the subducting crust. However, Liu et al. have not evaluated the effect of $\mathrm{Fe}$, which along with $\mathrm{H}$ are crucial in electrical conduction, and the question arises how convincing their results might be applied to Earth's interior. In this report, we have by experimental work measured the conductivity of omphacite and garnet from representative eclogites, which plus the samples of Liu et al. (2019) show a wide range of contents in $\mathrm{Fe}$ and $\mathrm{H}_{2} \mathrm{O}$. The data are used to infer the water contents of the minerals in the subducting crust, by combining with geophysically-based electrical structure and slab petrology. The results demonstrate clearly that a small amount of water is present in omphacite and garnet in deep subducting crusts.

\section{Experiments and Methods}

\subsection{Starting materials and sample characterization}

Three starting eclogites were from Bixiling (omp1 + grt1) and Shuanghe (omp3 + grt3) in China and Weißenstein (omp2 + grt2) in Germany, and were all related to slab subduction and exhumation (Franz et al., 1986; Sheng et al., 2007). The Weißenstein 
eclogite was studied in Liu et al. (2019). These samples were chosen by considering Fe contents of constituting omphacite and garnet and quality of grains from $>30$ eclogites (note: the electrical property of silicates is independent of the origin). Natural eclogites were not used for conductivity studies directly, because of the occurrence of accessory materials (e.g., secondary hydrous phases, fluid inclusions and/or other impurities) and zoned water distribution that affect conductivity analyses. We analyzed the conductivity of omphacite and garnet separately and then modeled the bulk conductivity. Omphacite and garnet are representative in composition, in particular in Fe that almost covers the content ranges in subduction-involved eclogites (omp1 and omp3: Appendix). Optically clear omphacite/garnet grains, $\sim 100-700 \mu \mathrm{m}$ in size, were handpicked under a binocular microscope. Each sample is chemically homogeneous in major-/minorelements (Table 1), as measured by a JEOL JXA-8230 electron microprobe (15 kV accelerating voltage, $10 \mathrm{nA}$ current and $<5 \mu \mathrm{m}$ beam size). Grains were ground to powder, mostly 30-80 $\mu \mathrm{m}$, and $\mathrm{H}$-annealed with minor distilled water in Ni capsules (ID $4.2 \mathrm{~mm}$, OD $5.0 \mathrm{~mm}$ and length $10 \mathrm{~mm})$ at 1-3.5 $\mathrm{GPa}$ and $650-700{ }^{\circ} \mathrm{C}(150-180 \mathrm{~h}$ duration) in a piston cylinder press. By this, water homogenization was achieved in each sample, and samples with different water contents were prepared. Dry samples were not prepared, because $\mathrm{OH}$ is common in natural omphacite and garnet. Recovered samples were cored into cylinders of $3 \mathrm{~mm}$ diameter and $1.7 \mathrm{~mm}$ length for subsequent conductivity runs, note that the conductivity of silicate minerals by lattice conduction is independent of grain size above $\sim 5 \mu \mathrm{m}$ that is typical for minerals in the deep Earth (Yang and Heidelbach, 2012).

A precise analysis of water content is key for evaluating its effect on conductivity. The general principle for water quantification in silicate minerals by Fourier-transform infrared (FTIR) spectroscopy is given by the modified Beer-Lambert law: $C_{\mathrm{H}}=A b s_{\text {total }} / I$, 
where $C_{\mathrm{H}}$ is $\mathrm{OH}$ content, $A b s_{\text {total }}$ is the total $\mathrm{OH}$ integrated absorbance normalized to 1 cm thickness, and $I$ is the mineral-specific integral molar absorption coefficient. As such, $C_{\mathrm{H}}$ is determined by $A b s_{\text {total }}$, once the coefficient $I$ is externally calibrated. For optically anisotropic minerals, the intensity of $\mathrm{OH}$ bands is sensitive to the orientation of the IR active dipole relative to incident beam, and $A b s_{\text {total }}$ is the sum of thicknessnormalized integrated absorbance along the three principal axes $(a, b$ and $c)$. This requires orienting samples and polarized FTIR analyses along the axes, which are difficult for small grains and are time-consuming for sample preparation. Recently, Shuai and Yang (2017) have shown that $A b s_{\text {total }}$ can be well characterized by polarized FTIR analyses along any three mutually perpendicular directions of a given sample, without the necessity to orient the samples; in case very small grains which are unable to be prepared for polarized FTIR work, Qiu et al. (2018) have demonstrated that $A b s_{\text {total }}$ can be obtained by unpolarized FTIR analyses on randomly oriented grains.

Water contents were measured by a Bruker Vertex 70V FTIR spectrometer coupled with a Hyperion 2000 microscope. Analyses were performed on optically clear grains with an aperture of $60 \times 60 \mu \mathrm{m}$ and a resolution of $4 \mathrm{~cm}^{-1}(128 \mathrm{scans}$ for each spectrum by a globar source, $\mathrm{KBr}-\mathrm{Ge}$ beam splitter, MCT detector and wire-grid Ze-Se polarizer). For anisotropic omphacite, polarized spectra were acquired for relatively large grains in annealed samples before conductivity runs (Shuai and Yang, 2017), and unpolarized spectra on 15-20 randomly oriented grains were obtained for fine-grained samples after conductivity runs (Qiu et al., 2018). For cubic garnet, unpolarized spectra were recorded over 6-9 grains. Water contents were calibrated by the mineral-specific coefficients of Katayama et al. (2006) for omphacite and garnet in eclogites, and uncertainty is mostly $<10 \%$, as documented in Shuai and Yang (2017) and Qiu et al. (2018). For a comparison under the same framework, the same calibration was used to recalculate the $\mathrm{H}_{2} \mathrm{O}$ content 
of minerals in natural eclogites in available studies. This yields values different from some early work, e.g., the $1840 \mathrm{ppm} \mathrm{OH}$ of omphacite in Smyth et al. (1991), estimated by the $\mathrm{OH}$ peak linear intensity, is actually $\sim 310 \mathrm{ppm} \mathrm{H}_{2} \mathrm{O}$; in contrast, the $\mathrm{H}_{2} \mathrm{O}$ contents of omphacite and garnet in recent reports (Katayama and Nakashima, 2003; Katayama et al., 2006; Sheng et al., 2007; Schmädicke and Gose, 2017) are less affected. The general results of this work are not affected by adopting the calibration coefficients.

\subsection{Conductivity experiments at elevated conditions}

Slabs are rather oxidizing above $\sim 200 \mathrm{~km}$ depth, with redox state similar to the $\mathrm{Ni}$ NiO buffer (McCammon, 2005). Therefore, conductivity runs were carried out with $\mathrm{Ni}$ $\mathrm{NiO}$ at $1-2.5 \mathrm{GPa}$ and $250-850^{\circ} \mathrm{C}$ in an end-loaded piston cylinder press. The assembly design resembles that in our previous studies (Yang et al., 2011, 2012; Yang, 2012; Yang and Heidelbach, 2012; Yang and McCammon, 2012; Li et al., 2016, 2017; Liu et al., 2019), and only a brief description is offered. In each run, a BN-Ni double capsule was adopted to maintain sample geometry and yield a relatively sealed chamber. BN causes reducing conditions only when $\mathrm{O}_{2}$ is rich (e.g., in air) and run duration is long above $\sim 1000{ }^{\circ} \mathrm{C}$, by $4 \mathrm{BN}+3 \mathrm{O}_{2}=2 \mathrm{~B}_{2} \mathrm{O}_{3}+2 \mathrm{~N}_{2}$, and $\mathrm{BN}$ itself in a sealed system does not influence the redox state. It has been demonstrated that, for the design at $<1000{ }^{\circ} \mathrm{C}$ and short duration (typical of conductivity runs), the reaction of $\mathrm{Pt}$ and $\mathrm{Fe}$ in samples is negligible and the redox state in the chamber is well buffered, as tested with pyroxenes and olivine (Yang et al., 2011, 2012; Yang, 2012; Yang and McCammon, 2012).

Before assembly, $\mathrm{Al}_{2} \mathrm{O}_{3}$ parts were heated at $1000{ }^{\circ} \mathrm{C}$ to remove absorbed water, and during assembly, no cement/glue was used to immobilize the various parts to avoid volatile release at high temperature that affects the analyses. Completed assembly was heated at $136{ }^{\circ} \mathrm{C}$ overnight, and was heated again at $200{ }^{\circ} \mathrm{C}$ after loading into the press. Impedance spectra were recorded in the heating-cooling cycles, with a Solartron 1260 
Impedance/Gain Phase analyser by frequency sweeping at $10^{6}-1 \mathrm{~Hz}$ and $0.5 \mathrm{~V}$ applied voltage. Temperature of the analyses was up to $850{ }^{\circ} \mathrm{C}$, to minimize water diffusion loss of samples upon heating. Duration was typically $\sim 1$ min or less per analysis (depending on temperature). After each run, recovered capsule was polished for optical, FTIR and backscattered electron examinations. Ni-NiO pairs were present, and sample distortions and grain growths were negligible, as observed in similar work (Yang et al., 2011, 2012; Yang, 2012; Yang and Heidelbach, 2012; Yang and McCammon, 2012; Li et al., 2017; Liu et al., 2019). Resistance $(R)$ was obtained from the impedance spectra (see below), and conductivity $(\sigma)$ was calculated by $\sigma=L / S R$, where $L$ and $S$ are the effective sample length and cross-section area, respectively. Uncertainty is usually $<5 \%$ for conductivity and $<20^{\circ} \mathrm{C}$ for temperature.

\section{Results}

Representative FTIR spectra of annealed samples are shown in Fig. 1. The spectra show absorption peaks at $3610-3625,3500-3520$ and $3440-3460 \mathrm{~cm}^{-1}$ in the omphacites and at 3610-3640 and 3530-3550 $\mathrm{cm}^{-1}$ in the garnets, which are typical of $\mathrm{OH}$ bands in the eclogite minerals (Smyth et al., 1991; Katayama and Nakashima, 2003; Katayama et al., 2006; Sheng et al., 2007; Schmädicke and Gose, 2017). In each mineral, the peak frequency positions are similar, suggesting similar $\mathrm{H}$ incorporation mechanism, and the relative difference of peak intensity between different samples are due to different water contents and/or grain orientations. Sample $\mathrm{H}_{2} \mathrm{O}$ contents are basically the same prior to and after each conductivity run (Table 2). Fe and other major-/minor-elements are more sluggish than $\mathrm{H}$, and their contents are unchanged in the runs. Representative complex spectra are presented in Fig. 2. The spectra usually show a high frequency arc and a low frequency tail, although the tail is sometimes not obvious, and the spectral shapes are similar to those reported for other minerals (Dai and Karato, 2009; Yoshino et al., 2009; 
Yang et al., 2011, 2012; Yang, 2012; Zhang et al., 2012, 2019; Zhao and Yoshino, 2016;

Li et al., 2016, 2017; Liu et al., 2019). The arc and tail was by sample lattice conduction and electrode effects, respectively.

The conductivity of NAMs (and other Earth materials) is quantitatively described by the Arrhenius relation:

$$
\sigma=\sigma_{0} \cdot \exp (-\Delta H / \mathrm{R} T)
$$

where $\sigma_{0}$ is a constant, $\Delta H$ is the activation enthalpy, $\mathrm{R}$ is the ideal gas constant, and $T$ is temperature. Conductivities in the first heating were sometimes affected by residual moisture in the chamber, yielding data not obeying Eq. (1) as observed in similar studies (Yang et al., 2012; Yang and Heidelbach, 2012; Li et al., 2017; Liu et al., 2019), and the influenced data were excluded. Conductivity data and the fittings to Eq. (1) are shown in Fig. 3, and fit parameters are given in Table 2. Sample conductivity is much greater than the assembly background conductivity (Yang et al., 2011). The data are consistent between different heating-cooling cycles in each run (see also Appendix), suggesting the absence of system hysteresis. The conductivity is slightly larger at 2.5 than at $1 \mathrm{GPa}$, indicated by the runs with an $\mathrm{OH}$-bearing omphacite (omp3). This is consistent with the previous study on an OH-bearing pyrope that shows similar conductivity enhancement by pressure (Dai and Karato, 2009). In contrast, the conductivity of dry olivine or garnet decreases slightly with increasing pressure (Xu et al., 2000; Dai and Karato, 2009). The difference is caused by the different pressure dependence between small polaron and $\mathrm{H}$ conduction in the minerals (see Section 4), but the effect of pressure (at a small variation) on the conductivity of silicate minerals is in general insignificant.

\section{Fe- and H-dependent conductivity}

In Fe- and H-bearing NAMs, the conductivity is related to the conduction of small 
polarons (electron-hole hopping between $\mathrm{Fe}^{2+}$ and $\mathrm{Fe}^{3+}$ ) and protons $(\mathrm{H})$. Our data show that, at otherwise identical conditions, the conductivity of both omphacite and garnet increases with $\mathrm{Fe}$ and $\mathrm{H}_{2} \mathrm{O}$ contents (Fig. 3), agreeing with studies on other NAMs (Dai and Karato, 2009; Yoshino et al., 2009; Yang et al., 2011, 2012; Yang and McCammon, 2012; Zhang et al., 2012; Zhao and Yoshino, 2016). The data trends of our omphacites are consistent with those of synthetic omphacites at $3 \mathrm{GPa}$ (Zhang et al., 2019), and the conductivity of the omphacite (omp3) with $7.92 \mathrm{wt} . \% \mathrm{FeO}$ and $70 \mathrm{ppm}_{2} \mathrm{O}$ is close to that of an augite with 8.31 wt.\% $\mathrm{FeO}$ and $75 \mathrm{ppm} \mathrm{H}_{2} \mathrm{O}$ at $1 \mathrm{GPa}$ (Yang and McCammon, 2012) (Fig. 3a). The conductivity of the omphacite (omp1) with $1.46 \mathrm{wt} . \%$ and $200 \mathrm{ppm}$ $\mathrm{H}_{2} \mathrm{O}$ resembles that of the one (omp2) with 4.27 wt.\% and 150-290 ppm $\mathrm{H}_{2} \mathrm{O}$, implying an insignificant effect of $\mathrm{Fe}$ at that content range. At a similar 155-160 ppm $\mathrm{H}_{2} \mathrm{O}$, the conductivity of the Fe-rich garnet $(15.40 \mathrm{wt} \% \mathrm{FeO})$ is less than that reported by Dai and Karato (2009) for a Fe-poor pyrope (7.42 wt.\% FeO) at 8 GPa (Fig. 3b). Probably, this is related to the different pressures ( 1 vs. $8 \mathrm{GPa}$ ) and $\mathrm{H}$-species (note that different H-defects could have different mobility, contributing differently to the conduction), e.g., narrow $\mathrm{OH}$ bands at $3700-3500 \mathrm{~cm}^{-1}$ in this study vs. broad bands at $3800-3000 \mathrm{~cm}^{-1}$ in Dai and Karato (2009). The conductivity of our garnets is close at similar contents of FeO (26.55-26.58 wt.\%) and $\mathrm{H}_{2} \mathrm{O}$ (100-110 ppm, with similar $\mathrm{OH}$ band shapes, Fig. 1). The activation enthalpy is Fe-dependent in omphacite, $\sim 87,81-84$ and $65 \mathrm{~kJ} / \mathrm{mol}$ at 1.64 , 4.27 and 7.92 wt.\% FeO, respectively, but is broadly Fe-independent in garnet, 88-91 $\mathrm{kJ} / \mathrm{mol}$ over a large range of Fe contents, 15.40-26.58 wt.\% FeO (Table 1). Therefore, the effect of $\mathrm{Fe}$ on the conductivity of omphacite and garnet is mineral dependent.

For the same omphacite or garnet in eclogite samples under similar conditions, the conductivity is linearly proportional to water content below $\sim 1000{ }^{\circ} \mathrm{C}$ and at moderate $\mathrm{H}_{2} \mathrm{O}$ contents (Liu et al., 2019; Zhang et al., 2019). This has also been reported for many 
other NAMs such as augite, diopside, enstatite, plagioclase, pyrope and olivine (Yang et al., 2011, 2012; Yang and McCammon, 2012; Zhang et al., 2012; Zhao and Yoshino, 2016). For an $\mathrm{OH}-$ bearing mineral with a fixed content of $\mathrm{Fe}$ (and other major elements), of proton conduction at relatively low temperature. Eq. (1) can be approximated by:

$$
\sigma \propto C_{H} \cdot \exp \left(-\Delta H_{H} / \mathrm{R} T\right)
$$

where $\Delta H_{\mathrm{H}}$ is the activation enthalpy by $\mathrm{H}$ conduction and is numerically equal to $\Delta H$ in Eq. (1). As such, the conductivity of both omphacite and garnet can be modeled for a range of $\mathrm{H}_{2} \mathrm{O}$ contents at each of the starting $\mathrm{FeO}$ contents (Fig. 4). The essentially same conductivity of omphacite with 1.64 and 4.27 wt.\% FeO at the same $\mathrm{H}_{2} \mathrm{O}$ content, as noted above, indicates a more significant role of $\mathrm{H}$ than $\mathrm{Fe}$ at such Fe content levels.

The N-type semiconductor relation is used to model the effect of both $\mathrm{Fe}$ and $\mathrm{H}$ on the conductivity of both minerals:

$$
\sigma=A \cdot X_{F e}^{n} \cdot C_{H} \cdot \exp \left[-\left(\Delta E-\alpha X_{F e}^{1 / 3}-\beta C_{H}^{1 / 3}\right) / \mathrm{R} T\right]
$$

255 where $X_{F e}$ is the molar fraction of $\mathrm{Fe}(=\mathrm{Fe} /(\mathrm{Fe}+\mathrm{Mg})), \Delta E$ is the activation energy, and $A, n, \alpha$ and $\beta$ are constants. The insensitivity of omphacite conductivity to $\mathrm{FeO}$ content at 1.64-4.27 wt.\% makes it hard to model the whole dataset with Eq. (3). In this context, the modeling is carried out for omphacite using the conductivity data of our samples with similar $\mathrm{OH}$ band positions) of Zhang et al. (2019), and for garnet using the data of all our samples (the Dai and Karato (2009) pyropes are not used because of the different $\mathrm{OH}$ bands). This yields $\Delta E, A, n, \alpha$ and $\beta$ of $106 \pm 6 \mathrm{~kJ} / \mathrm{mol}, 2754 \pm 380 \mathrm{~S} / \mathrm{m},-0.05 \pm 0.09$, $64 \pm 6 \mathrm{~kJ} / \mathrm{mol}$ and $-26 \pm 8 \mathrm{~kJ} / \mathrm{mol}$ for omphacite, and $89 \pm 3 \mathrm{~kJ} / \mathrm{mol}, 61660 \pm 4085 \mathrm{~S} / \mathrm{m}$, 
results by Eq. (2) and (3) are well consistent at the same $\mathrm{H}_{2} \mathrm{O}$ and boundary Fe contents, especially at $>500{ }^{\circ} \mathrm{C}$ (Fig. 4).

The bulk conductivity of eclogite is calculated from omphacite and garnet with the Hashin and Shtrikman (1962) bounds, which offer the narrowest restrictions of a twophase composite despite the geometrical configurations:

$$
\begin{aligned}
& \sigma_{H S+}=\sigma_{1}+x_{2}\left[\left(\sigma_{2}-\sigma_{1}\right)^{-1}+x_{1} /\left(3 \sigma_{1}\right)\right]^{-1} \\
& \sigma_{H S-}=\sigma_{2}+x_{1}\left[\left(\sigma_{1}-\sigma_{2}\right)^{-1}+x_{2} /\left(3 \sigma_{2}\right)\right]^{-1}
\end{aligned}
$$

where $\sigma_{\mathrm{HS}}$ and $\sigma_{\mathrm{HS}}$ are the upper and lower bounds, respectively, given $\sigma_{1}>\sigma_{2}(x$ is the volume proportion). A key prerequisite for the modeling is the equilibrium distribution of major/minor elements and $\mathrm{OH}$ between coexisting minerals. This is a factor that must be considered when modeling the bulk conductivity of any matrix consisting of several phases. The calculation is carried out by Eq. (2) using the conductivity data of minerals at different $\mathrm{H}_{2} \mathrm{O}$ contents for each starting Fe content, in which case the effect of $\mathrm{Fe}$ is constrained at the same time (Fig. 4). Eq. (3) is not adopted, because of the difficulty in controlling chemical equilibrium between the two minerals. Each of the mineral pairs, omp1-grt1, omp2-grt2 and omp3-grt3, was separated from the same starting eclogite, and the major/minor elements are already in equilibrium. The water partition coefficient between omphacite and garnet in eclogite, $\sim 0.2$ from Katayama et al. (2006), is adopted to obtain the equilibrium $\mathrm{H}_{2} \mathrm{O}$ contents (assuming 100, 200 and $400 \mathrm{ppm}$ in omphacite). The bulk conductivity of eclogite is not affected by likely minor impurities, because if present, they are usually isolated (not connected) in the matrix and do not contribute to bulk conduction. The results are shown in Fig. 5a and $\mathrm{b}$ for omphacite-rich and garnetrich rocks, respectively. This produces the modeled bulk conductivity at variable Fe and $\mathrm{H}_{2} \mathrm{O}$ contents and high temperature. In particular, The $\mathrm{FeO}$ contents reflect the range of the two minerals in subducting crusts (as noted before). Given other conditions, $\sigma_{\mathrm{HS}}+$ 
and $\sigma_{\text {HS- }}$ of each sample show a small variation above $600{ }^{\circ} \mathrm{C}$, and are up to $\sim 0.1 \mathrm{~S} / \mathrm{m}$ at $900{ }^{\circ} \mathrm{C}$ (for the modeled composition). Considering the positive pressure effect on the conductivity of $\mathrm{OH}$-bearing omphacite and garnet as mentioned above, the bulk conductivity is only slightly greater at higher pressure.

\section{Water contents in subducting omphacite and garnet}

Electromagnetic induction is sensitive to conductive rather than resistive bodies in Earth's interior. This makes it hard to accurately resolve the conductivity of subducting crusts that are highly resistive. Usually, high conductivity is not detected in subducting slabs, and slab conductivity is much smaller than that of mantle wedge and surrounding mantle in the inversion results. Conductivity of the subducting crust, either fast or slow subduction in diverse settings, is estimated to be mostly $10^{-4}$ to $10^{-3} \mathrm{~S} / \mathrm{m}$ at $\sim 70-120 \mathrm{~km}$ depth (Vanyan et al., 2002; McGary et al., 2014; Ichiki et al., 2015; Vargas et al., 2019). This is a reasonable estimate by imposing a 1000,5000 or $10000 \Omega$ slab resistivity in the inversion models (Ichiki et al., 2015). A typical electrical structure of a subducting crust is given in Fig. 5c (after McGary et al. (2014) who focused on conductive channels in the wedge). We want to note that, although Evans et al. (2014) have offered a variety of outputs (mainly in the wedge) with the same electromagnetic data of McGary et al. (2014) by applying different inversion methods, the crust portion at $\sim 70-120 \mathrm{~km}$ depth is very resistive in most of their models. Moreover, Fig. $5 \mathrm{c}$ is for the Cascadia area, but broadly similar results on resistive slab vs. depth have been reported for other tectonic environments (e.g., Vanyan et al., 2002; Ichiki et al., 2015; Vargas et al., 2019).

It has been shown that, despite a wide range of ages, geometries and convergence rates, slabs actually share many common features with their thermal structures (Peacock, 1996; Syracuse et al., 2010; Penniston-Dorland et al., 2015). At 70-120 km depth, the temperature is mostly $\sim 600-900{ }^{\circ} \mathrm{C}$ in the crust layer, for subduction zones over various 
tectonic settings. The FeO content is $\sim 1-8 \mathrm{wt} . \%$ of omphacite and $14-27 \mathrm{wt} . \%$ of garnet in terrane eclogites that were once brought to $\sim 200 \mathrm{~km}$ depth (Katayama and Nakashima, 2003; Katayama et al., 2006; Sheng et al., 2007; and Appendix), suggesting that deeply subducting eclogites are in fact not depleted in Fe. As such, to cause the $10^{-4}-10^{-3} \mathrm{~S} / \mathrm{m}$

conductivity of subducting crusts at $\sim 600-900{ }^{\circ} \mathrm{C}$, the only possibility is that omphacite and garnet are water-poor. According to the modeling in Fig. 5a-b, the $\mathrm{H}_{2} \mathrm{O}$ contents are $<400 \mathrm{ppm}$ in omphacite and $<80 \mathrm{ppm}$ in garnet at $600{ }^{\circ} \mathrm{C}$ and $<100 \mathrm{ppm}$ in omphacite and $<20 \mathrm{ppm}$ in garnet at $900{ }^{\circ} \mathrm{C}$ for the bottom Fe boundaries (omp1-grt1), and $<30$ ppm for the top Fe boundaries (omp3-grt3). These $\mathrm{H}_{2} \mathrm{O}$-content ranges are meaningful, in particular if considering the weaker effect of a minor variation in $\mathrm{Fe}$ than in $\mathrm{H}$ content (Section 4), and can be even smaller, if the effect of pressure on the conductivity of $\mathrm{OH}$ bearing omphacite and garnet is considered (Section 3). The maximum $<400 \mathrm{ppm}_{2} \mathrm{O}$ content resembles that estimated in Liu et al. (2019), which is based on omp2 in contrast to omp1 in this study (due to the more significant effect of $\mathrm{H}$ at the Fe content levels as noted above). The inferred $\mathrm{H}_{2} \mathrm{O}$ contents of omphacite and garnet in subducting crusts ( 70-120 km depth) are much less than those up to 2000-3000 ppm in terrane eclogites (Katayama and Nakashima, 2003; Katayama et al., 2006). This suggests that OH-rich omphacite and garnet in the terrane samples were H-enriched by secondary processes during their exhumation to surface, in line with the arguments by analyzing mineral $\mathrm{OH}$ patterns and D/H ratios (Sheng et al., 2007; Schmädicke and Gose, 2017). Interestingly, the $\mathrm{H}_{2} \mathrm{O}$ values resemble the mostly $<360$ ppm of omphacite and $<65$ ppm of garnet in volcano-hosted xenolith eclogites (Smyth et al., 1991; Bell and Rossman, 1992; KochMüller et al., 2004). This makes more sense if xenolith eclogites represent the various dehydrated products of subducted crusts that were accidently entrained by volcanoes and transferred to the surface; however, things could be complicated because a general 
consensus has not been reached for the origin of xenolith eclogites, e.g., some may form by melt accumulation (Jacob, 2004).

Consequently, the conductivity data and inferred water contents of omphacite and garnet are broadly consistent with the constraints from other approaches. The inversion of electromagnetic data at subduction zones has long been subjected to the difficulty in adopting a good reference resistor in the starting model. In most cases, the inversion is carried out by highlighting the conductivity contrast between the resistive slab and the conductive paths in the wedge (linked to melting and/or dehydrated fluids). In order to identify fine-scale variation of conductivity in the subducting slab, e.g., due to change of temperature and release of water with subduction, it is important to impose a reliable slab conductivity in the inversion model. The water contents of minerals in the slab, the electrical properties of eclogites and the conductivity laws, as provided here, allow to model the conductivity of oceanic crusts as a function of temperature and water content as the starting reference resistor for the inversion of electromagnetic data.

\section{Implications for deep water recycling}

The very low water contents of omphacite and garnet at $\sim 70-120 \mathrm{~km}$ depth imply a much smaller water content in the subducting crust than the original value dominated by hydrous phases (e.g., amphibole and chlorite), e.g., 1-2 wt.\% $\mathrm{H}_{2} \mathrm{O}$ (Peacock, 1990). Water in the subducting crust is mostly released at shallow depths, and the dehydration of hydrous phases and omphacite and garnet in eclogites produces conductive channels in the wedge (McGary et al., 2014). Eclogite-facies metamorphism, which involves all materials in the system, occurs at $>30 \mathrm{~km}$ depths in the subducting crust (e.g., Peacock, 1990; Schmidt and Poli, 2014). The inferred small water contents of omphacite and garnet are indicative of extremely water-poor conditions, or very low water activity, during the metamorphism and in the system. Otherwise, the water contents of the two 
minerals would dramatically increase, due to their strong ability in accommodating $\mathrm{OH}$ (Katayama and Nakashima, 2003; Katayama et al., 2006; Sheng et al., 2007), and their conductivity would be greatly enhanced, leading to conductive zones in the subducting slab that is inconsistent with geophysical mappings (Vanyan et al., 2002; McGary et al., 2014; Ichiki et al., 2015; Vargas et al., 2019). The water-poor conditions also imply very minor to negligible amounts of hydrous phases in the system, because of their extensive dehydration and water escape at shallow depths. This agrees with the arguments that subducting crusts may contain no hydrous minerals beyond $\sim 3 \mathrm{GPa}$ and $700{ }^{\circ} \mathrm{C}$, as advocated by considering dehydration in natural rocks, numerical modeling and phase stabilities (Liu et al., 1996; Schmidt and Poli, 2014).

In this context, the amount of water carried to the deep mantle by subducting crust is regulated by omphacite and garnet in eclogites, but not hydrous phases. This implies a minor amount of water that could be brought to the deep mantle, although it might be significant at very shallow depths (Peacock, 1990; Cai et al., 2018). Assuming the total length, thickness and density of subducting oceanic crusts of $40000 \mathrm{~km}$ (Syracuse et al., 2010), $6 \mathrm{~km}$ and $3 \mathrm{~g} / \mathrm{cm}^{3}$, respectively, and the average rate of subduction of $5 \mathrm{~cm} /$ year, the mass of water transferred to the mantle exceeding $\sim 70 \mathrm{~km}$ depth in the past 3 billion years would correspond to $<3 \%$ of the oceans. A direct implication is that the exchange of water between Earth's exterior and interior reservoirs might not be efficient. This fits well with the high dehydration efficiency ( $>92 \%)$ of subducting crusts at shallow depths, estimated from the $\mathrm{H}_{2} \mathrm{O} / \mathrm{Ce}$ ratios of mid-ocean ridge basalts (Dixon et al., 2002), and the preservation of protosolar nebular water in the deep mantle over Earth's evolution, constrained by the $\mathrm{D} / \mathrm{H}$ ratios of plume-related lavas (Hallis et al., 2015). The limited water transfer by crust deep subduction does not mean a water-poor deep Earth, because surface water (and atmosphere) formed by degassing of the Earth (Allègre et al., 1987) 
and its deep interior was already hydrous.

Consequently, the water flux into the deep mantle is much smaller than that simply estimated from the stabilities of hydrous minerals such as amphibole, chlorite and dense hydrous magnesium silicates, by assuming their continuous presence in appreciated amounts in the downgoing crust. The stability fields of hydrous phases are established by experiments at water saturated/super-saturated conditions, e.g., with up to $>10 \mathrm{wt.} \%$ water in sealed capsules (Liu et al., 1996; Frost, 2006; Schmidt and Poli, 2014). This requirement is hard to always fulfil in the subducting crust that is not a closed system and contains an initial $\mathrm{H}_{2} \mathrm{O}$ content of $\sim 1-2$ wt.\% prior to subduction (Peacock, 1990), which is mostly released at shallow depths. Thus, there is a gap between the water-poor state in the deep slab and the water-rich state in laboratory. Finally, if slab mantle bears serpentine, e.g., by the serpentinization of peridotites providing there is enough water for serpentine formation prior to subduction, then its role in conveying water to Earth's interior should be evaluated. Key to this issue is to map the actual amount of serpentine in the slab mantle and the dynamics of the low density with subduction, e.g., $2.6 \mathrm{~g} / \mathrm{cm}^{3}$ of serpentine vs. $3.4 \mathrm{~g} / \mathrm{cm}^{3}$ of peridotite and $3.6 \mathrm{~g} / \mathrm{cm}^{3}$ of eclogite. This is beyond the scope of this work, and more studies are required.

\section{Acknowledgements}

We thank Lingmin Zhang for assistance with microprobe analyses and Charles Geiger for some text polishing on an early version. X.Y. is deeply indebted to Masahiro Ichiki and Philip Wannamaker for clarifying the electrical structure of subducting slab and the technical issues of electromagnetic work. X.Y. thanks Joseph Smyth and Monika KochMüller for discussions. Editorial handling by James Badro and comments by Fabrice Gaillard and one anonymous reviewer helped to improve the manuscript. This study was supported by National Science Foundation of China (41725008) and National Key 


\section{References}

416

Allègre, C.J., Staudacher, T., Sarda, P., 1987. Rare gas systematics: formation of the atmosphere, evolution and structure of the Earth's mantle. Earth Planet. Sci. Lett. 81, 127-150.

Bell, D.R., Rossman, G.R., 1992. Water in Earth's mantle: the role of nominally anhydrous minerals. Science 255, 1391-1397.

Bromiley, G.D., Keppler, H., 2004. An experimental investigation of hydroxyl solubility in jadeite and Na-rich clinopyroxenes. Contrib. Mineral. Petrol. 147, 189-200.

Cai, C., Wiens, D.A., Shen, W., Eimer, M., 2018. Water input into the Mariana subduction zone estimated from ocean-bottom seismic data. Nature 563, 389-392.

Dai, L., Karato, S.I., 2009. Electrical conductivity of pyrope-rich garnet at high temperature and high pressure. Phys. Earth Planet. Inter. 176, 83-88.

Dixon, J.E., Leist, L., Langmuir, C.H., Schilling, J.G., 2002. Recycled dehydrated lithosphere observed in plume-influenced mid-ocean-ridge basalt. Nature 420, 385-389.

Evans, R.L., Wannamaker, P.E., McGary, R.S., Elsenbeck, J., 2014. Electrical structure of the central Cascadia subduction zone: The EMSLAB Lincoln Line revisited. Earth Planet. Sci. Lett. 402, 265-274.

Franz, G., Thomas, S., Smith, D.C., 1986. High-pressure phengite decomposition in the Weissenstein eclogite, Münchberger Gneiss Massif, Germany. Contrib. Mineral. Petrol. 92, 71-85.

Frost, D.J., 2006. The stability of hydrous mantle phases. Rev. Mineral. Geochem. 62, 243-271.

Hallis, L.J., Huss, G.R., Nagashima, K., Taylor, G.J., Halldórsson, S.A., Hilton, D.R., Mottl, M.J., Meech, K.J., 2015. Evidence for primordial water in Earth's deep mantle. Science 350, 795-797.

Hashin, Z., Shtrikman, S., 1962. A variational approach to the theory of the effective magnetic permeability of multiphase materials. J. Appl. Phys. 33, 3125-3131.

Ichiki, M., Ogawa, Y., Kaida, T., Koyama, T., Uyeshima, M., Demachi, T., Hirahara, S., Honkura, Y., Kanda, W., Kono, T., Matsushima, M., Nakayama, T., Suzuki, S., Toh, H., 2015. Electrical image of subduction zone beneath northeastern Japan. J. Geophys. Res. 120, 7937-7965.

Ito, E., Harris, D.M., Anderson Jr, A.T., 1983. Alteration of oceanic crust and geologic cycling of chlorine and water. Geochim. Cosmochim. Acta 47, 1613-1624.

Jacob, D.E., 2004. Nature and origin of eclogite xenoliths from kimberlites. Lithos 77, 295-316.

Karato, S., 1990. The role of hydrogen in the electrical conductivity of the upper mantle. Nature 347, 272-273.

Katayama, I., Nakashima, S., 2003. Hydroxyl in clinopyroxene from the deep subducted crust: evidence for $\mathrm{H} 2 \mathrm{O}$ transport into mantle. Am. Mineral. 88, 229-234.

Katayama, I., Nakashima, S., Yurimoto, H., 2006. Water content in natural eclogite and implication for water transport into the deep upper mantle. Lithos 86, 245-259.

Koch-Müller, M., Matsyuk, S., Wirth, R., 2004. Hydroxyl in omphacites and omphacitic clinopyroxenes of upper mantle to lower crustal origin beneath the Siberian platform. Am. Mineral. 89, 921-931.

Li, Y., Yang, X., Yu, J.H., Cai, Y.F., 2016. Unusually high electrical conductivity of phlogopite: the possible role of fluorine and geophysical implications. Contrib. Mineral. Petrol. 171:37, 10.1007/s00410-016-1252-X.

Li, Y., Jiang, H., Yang, X., 2017. Fluorine follows water: Effect on electrical conductivity of silicate minerals by experimental constraints from phlogopite. Geochim. Cosmochim. Acta 217, 16-27.

Liu, J., Bohlen, S.R., Ernst, W.G., 1996. Stability of hydrous phases in subducting oceanic crust. Earth Planet. Sci. Lett. 143, 161-171.

Liu, H., Zhu, Q., Yang, X., 2019. Electrical conductivity of OH-bearing omphacite and garnet in eclogite: the quantitative dependence on water content. Contrib. Mineral. Petrol. 176: 57, 10.1007/s00410-019-1593-3.

Lu, R., Keppler, H., 1997. Water solubility in pyrope to 100 kbar. Contrib. Mineral. Petrol. 129, 3542.

McCammon, C., 2005. The paradox of mantle redox. Science 308, 807-808.

McGary, R.S., Evans, R.L., Wannamaker, P.E., Elsenbeck, J., Rondenay, S., 2014. Pathway from subducting slab to surface for melt and fluids beneath Mount Rainier. Nature 511, 338-340.

Peacock, S.M., 1996. Thermal and petrologic structure of subduction zones. Subduction Top Bottom 
96, 119-133.

Peacock, S.M., 1990. Fluid processes in subduction zones. Science 248, 329-337.

Penniston-Dorland, S.C., Kohn, M.J., Manning, C.E., 2015. The global range of subduction zone thermal structures from exhumed blueschists and eclogites: Rocks are hotter than models. Earth Planet. Sci. Lett. 428, 243-254.

Qiu, Y., Jiang, H., Kovacs, I., Xia, Q.-K., Yang, X., 2018. Quantitative analysis of H-species in anisotropic minerals by unpolarized infrared spectroscopy: An experimental evaluation. Am. Mineral. 103, 1761-1769.

Schmädicke, E., Gose, J., 2017. Water transport by subduction: clues from garnet of Erzgebirge UHP eclogite. Am. Mineral. 102, 975-986.

Schmidt, M.W., Poli, S., 2014. Devolatilization During Subduction, in: Treatise on Geochemistry. pp. 669-701.

Sheng, Y.M., Xia, Q.K., Dallai, L., Yang, X.Z., Hao, Y.T., 2007. $\mathrm{H}_{2} \mathrm{O}$ contents and D/H ratios of nominally anhydrous minerals from ultrahigh-pressure eclogites of the Dabie orogen, eastern China. Geochim. Cosmochim. Acta 71, 2079-2103.

Shuai, K., Yang, X., 2017. Quantitative analysis of H-species in anisotropic minerals by polarized infrared spectroscopy along three orthogonal directions. Contrib. Mineral. Petrol. 172, 14, doi: 10.1007/s00410-017-1336-2.

Smyth, J.R., Bell, D.R., Rossman, G.R., 1991. Incorporation of hydroxyl in upper-mantle clinopyroxenes. Nature 351, 732-735.

Syracuse, E.M., van Keken, P.E., Abers, G.A., 2010. The global range of subduction zone thermal models. Phys. Earth Planet. Inter. 183, 73-90.

Van Keken, P.E., Kiefer, B., Peacock, S.M., 2002. High-resolution models of subduction zones: Implications for mineral dehydration reactions and the transport of water into the deep mantle. Geochem. Geophys. Geosyst. 3, 10.1029/2001GC000256.

Vanyan, L.L., Berdichevsky, M.N., Pushkarev, P.Y., Romanyuk, T.V., 2002. A geoelectric model of the Cascadia subduction zone. Izv. Phys. Solid Earth 38, 816-845.

Vargas, J.A., Meqbel, N.M., Ritter, O., Brasse, H., Weckmann, U., Yáñez, G., Godoy, B., 2019. Fluid distribution in the Central Andes subduction zone imaged with magnetotellurics. J. Geophys. Res. 124, 4017-4034.

Xu, Y., Shankland, T.J., Duba, A.G., 2000. Pressure effect on electrical conductivity of mantle olivine. Phys. Earth Planet. Inter. 118, 149-161.

Yang, X., 2012. Orientation-related electrical conductivity of hydrous olivine, clinopyroxene and plagioclase and implications for the structure of the lower continental crust and uppermost mantle. Earth Planet. Sci. Lett. 317-318, 241-250.

Yang, X., Heidelbach, F., 2012. Grain size effect on the electrical conductivity of clinopyroxene. Contrib. Mineral. Petrol. 163, 939-947.

Yang, X., Keppler, H., Li, Y., 2016. Molecular hydrogen in mantle minerals. Geochem. Perspect. Lett. 2, 160-168.

Yang, X., Keppler, H., McCammon, C., Ni, H., 2012. Electrical conductivity of orthopyroxene and plagioclase in the lower crust. Contrib. Mineral. Petrol. 163, 33-48.

Yang, X., Keppler, H., McCammon, C., Ni, H., Xia, Q., Fan, Q., 2011. The effect of water on the electrical conductivity of lower crustal clinopyroxene. J. Geophys. Res. 116, B04208, 10.1029/2010JB008010.

Yang, X., McCammon, C., 2012. Fe ${ }^{3+}$-rich augite and high electrical conductivity in the deep lithosphere. Geology 40, 131-134.

Yoshino, T., Matsuzaki, T., Shatskiy, A., Katsura, T., 2009. The effect of water on the electrical conductivity of olivine aggregates and its implications for the electrical structure of the upper mantle. Earth Planet. Sci. Lett. 288, 291-300.

Zhang, B., Yoshino, T., Wu, X.P., Matsuzaki, T., Shan, S., Katsura, T., 2012. Electrical conductivity of enstatite as a function of water content: implications for the electrical structure in the upper mantle. Earth Planet. Sci. Lett. 357-358, 11-20.

Zhang, B., Zhao, C., Ge, J., Yoshino, T., 2019. Electrical conductivity of omphacite as a function of water content and implications for high conductivity anomalies in the Dabie-Sulu UHPM belts and Tibet. J. Geophys. Res. 124, 12523-12536.

Zhao, C., Yoshino, T., 2016. Electrical conductivity of mantle clinopyroxene as a function of water content and its implication on electrical structure of uppermost mantle. Earth Planet. Sci. Lett. 
447, 1-9. 


\section{Figure captions}

Fig. 1 Representative FTIR spectra of annealed omphacite and garnet. (a) polarized spectra of omphacite along three orthogonal directions of each grain $\left(X^{\prime}, Y^{\prime}\right.$ and $\left.Z^{\prime}\right)$, and (b) unpolarized spectra of garnet from different grains. The omp2 and grt2 spectra were reproduced from Liu et al. (2019). Spectra were normalized to $1 \mathrm{~cm}$ thickness and vertically offset.

Fig. 2 Representative complex spectra of (a) omphacite (B260) and (b) garnet (B256). $\mathrm{Z}^{\prime} / \mathrm{Z}^{\prime \prime}$ is the real/imaginary part of complex impedance, and frequency decreases along the $\mathrm{Z}^{\prime}$ axis from left $(1 \mathrm{MHz})$ to right $(1 \mathrm{~Hz})$. An equivalent circuit of a single $R$-CPE, a resistor $(R)$ and a constant phase element (CPE) in parallel, was used to fit the highfrequency arc. Tail and data scatter at low frequency were due to electrode effects that did not affect sample lattice resistance measurements. Number close to each spectrum is temperature $\left({ }^{\circ} \mathrm{C}\right)$, and inset in (a) shows spectra at $600-700{ }^{\circ} \mathrm{C}$.

Fig. 3 Measured conductivity of (a) omphacite and (b) garnet at 1-2.5 GPa and 250$850{ }^{\circ} \mathrm{C}$. The run at $2 \mathrm{GPa}$ was marked, and lines are linear fittings to measured data of each sample (with $\mathrm{H}_{2} \mathrm{O}$ contents labeled) by Eq. (1). Symbols around each line are from the same sample (different symbols for different cycles). Samples omp2 and grt2 were from Liu et al. (2019). Uncertainty is usually smaller than/comparable to symbol sizes. Data sources: assembly background, Yang et al. (2011); Z19, synthetic omphacites in Zhang et al. (2019) at $3 \mathrm{GPa}\left(0 \% \mathrm{FeO}\right.$ and $280 \mathrm{ppm} \mathrm{H}_{2} \mathrm{O}$ and $5.81 \% \mathrm{FeO}$ and $420 \mathrm{ppm}$ $\mathrm{H}_{2} \mathrm{O}$, with $\mathrm{H}_{2} \mathrm{O}$ contents recalculated (see text)); Y12, augite in Yang and McCammon (2012) at $1 \mathrm{GPa}\left(8.31 \% \mathrm{FeO}\right.$ and $\left.75 \mathrm{ppm} \mathrm{H}_{2} \mathrm{O}\right)$; D09, pyrope in Dai and Karato (2009)

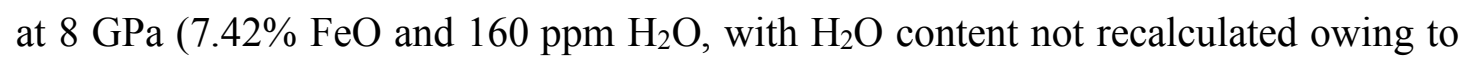
the different $\mathrm{OH}$ bands).

Fig. 4 Modeled conductivity of (a) omphacite and (b) garnet at various $\mathrm{FeO}$ and $\mathrm{H}_{2} \mathrm{O}$ 
contents. Colored solid lines were made using Eq. (2), and dashed and dotted grey lines were plotted using Eq. (3) for the bottom and top boundaries of FeO content (omp1 and omp3: see text), respectively. $\mathrm{H}_{2} \mathrm{O}$ contents of 100,200 and $400 \mathrm{ppm}$ in omphacite and 20, 40 and 80 ppm in garnet at equilibrium $\mathrm{OH}$ partitioning were assumed (see text).

Fig. 5 Electrical conductivity of eclogites with different modal composition and Fe and $\mathrm{H}_{2} \mathrm{O}$ contents. (a) omp-rich ( 65 vol. $\%$ omp +35 vol. $\%$ grt) eclogite, (b) grt-rich (35 vol. \% omp +65 vol. \% grt) eclogite, and (c) a typical conductivity-temperature structure along subduction zones (modified after McGary et al. (2014): note that some reference resistivities were imposed in their starting inversion model: see text). Modeling in (a, b) was conducted with the mineral data in Fig. 4 and Eq. (4): blue, red and green colors highlight the different $\mathrm{FeO}$ contents, omp1 + grt1, omp2 + grt2 and omp3 + grt3 (with labels on the right side), and star symbols denote different $\mathrm{OH}$ contents in the minerals. Horizontal/vertical shadows in $(a, b)$ show the conductivity/temperature range of the subducting crust at $\sim 70-120 \mathrm{~km}$ depth in (c). 
566 Table 1 Composition of the starting omphacite and garnet (by wt.\%)

\begin{tabular}{lllllllllll}
\hline & $\mathrm{SiO}_{2}$ & $\mathrm{TiO}_{2}$ & $\mathrm{Al}_{2} \mathrm{O}_{3}$ & $\mathrm{FeO}$ & $\mathrm{MnO}$ & $\mathrm{MgO}$ & $\mathrm{CaO}$ & $\mathrm{Na}_{2} \mathrm{O}$ & $\mathrm{K}_{2} \mathrm{O}$ & Total \\
\hline omp1 & 56.84 & 0.03 & 9.59 & 1.64 & 0.02 & 10.57 & 15.39 & 5.72 & 0.01 & 99.81 \\
& 0.42 & 0.02 & 0.07 & 0.03 & 0.01 & 0.30 & 0.09 & 0.03 & 0.01 & \\
omp2* & 55.64 & 0.07 & 11.38 & 4.27 & 0.02 & 8.44 & 12.98 & 7.31 & $<0.01$ & 100.11 \\
& 0.16 & 0.03 & 0.35 & 0.28 & 0.02 & 0.17 & 0.40 & 0.24 & $<0.01$ & \\
omp3 & 55.37 & 0.05 & 7.87 & 7.92 & 0.04 & 8.39 & 13.54 & 6.64 & $<0.01$ & 99.82 \\
& 0.26 & 0.01 & 0.08 & 0.15 & 0.04 & 0.03 & 0.08 & 0.16 & $<0.01$ & \\
grt1 & 39.48 & 0.05 & 22.22 & 15.40 & 0.29 & 9.33 & 12.24 & $<0.01$ & $<0.01$ & 99.01 \\
& 0.15 & 0.03 & 0.07 & 0.17 & 0.01 & 0.18 & 0.19 & $<0.01$ & $<0.01$ & \\
grt2* & 37.64 & 0.03 & 22.73 & 26.55 & 0.74 & 6.81 & 5.63 & 0.03 & $<0.01$ & 100.16 \\
& 0.20 & 0.02 & 0.12 & 0.36 & 0.08 & 0.17 & 0.32 & 0.02 & $<0.01$ & \\
grt3 & 37.49 & 0.07 & 21.63 & 26.58 & 0.14 & 5.02 & 8.79 & 0.04 & $<0.01$ & 99.76 \\
& 0.15 & 0.04 & 0.10 & 0.07 & 0.04 & 0.10 & 0.03 & 0.02 & $<0.01$ & \\
\hline
\end{tabular}

567 Assuming all $\mathrm{Fe}$ as FeO. Data are the average and standard deviation (italic) by electron

568 microprobe analyses. omp, omphacite; grt, garnet.

$569 *$ : data were reproduced from Liu et al. (2019) (see text). 
Table 2 Summary of samples and fit parameters

\begin{tabular}{|c|c|c|c|c|c|c|c|c|}
\hline Sample & $\mathrm{FeO}$ (wt.\%) & $P(\mathrm{GPa})$ & $T\left({ }^{\circ} \mathrm{C}\right)$ & ppm $\mathrm{H}_{2} \mathrm{O}$ (initial) & ppm $\mathrm{H}_{2} \mathrm{O}$ (final) & $L / S\left(\mathrm{~m}^{-1}\right)$ & $\log _{10}\left(A_{0}(\mathrm{~S} / \mathrm{m})\right)$ & $\Delta H(\mathrm{~kJ} / \mathrm{mol})$ \\
\hline B255 (omp1) & 1.64 & 1 & $350-700$ & 200 & 190 & 288 & $1.97 \pm 0.01$ & $87 \pm 2$ \\
\hline B185 (omp2)* & 4.27 & 1 & $350-600$ & 85 & 80 & 290 & $1.38 \pm 0.24$ & $84 \pm 4$ \\
\hline B149 (omp2)* & 4.27 & 1 & $350-600$ & 150 & 160 & 216 & $1.52 \pm 0.14$ & $82 \pm 2$ \\
\hline B145 (omp2)* & 4.27 & 1 & $350-650$ & 290 & 300 & 269 & $1.75 \pm 0.12$ & $81 \pm 2$ \\
\hline B260 (omp3) & 7.92 & 1 & $250-700$ & 70 & 70 & 280 & $1.21 \pm 0.07$ & $64 \pm 1$ \\
\hline B261 (omp3) & 7.92 & 2.5 & $250-700$ & 70 & 65 & 285 & $1.45 \pm 0.04$ & $65 \pm 1$ \\
\hline B256 (grt1) & 15.40 & 1 & $350-800$ & 155 & 150 & 340 & $1.89 \pm 0.18$ & $93 \pm 3$ \\
\hline B167 (grt2)* & 26.55 & 1 & $350-800$ & 40 & 45 & 226 & $1.80 \pm 0.17$ & $90 \pm 3$ \\
\hline B174 (grt2)* & 26.55 & 1 & $350-800$ & 100 & 95 & 245 & $2.26 \pm 0.12$ & $91 \pm 2$ \\
\hline B267 (grt3) & 26.58 & 1 & $350-850$ & 110 & 110 & 246 & $2.15 \pm 0.13$ & $88 \pm 2$ \\
\hline
\end{tabular}

571 Water contents are the values prior to (initial) and after (final) conductivity runs, and are rounded to the nearest $5 \mathrm{ppm}$. $L / S$ is the ratio of

572 sample length to cross-section area (by considering the effective contact between electrodes and sample). FeO contents of the samples are

573 shown (from Table 1).

$574 *$ : samples were used in Liu et al. (2019) for documenting the water content exponent of 1 in Eq. (2). 
Fig. 1

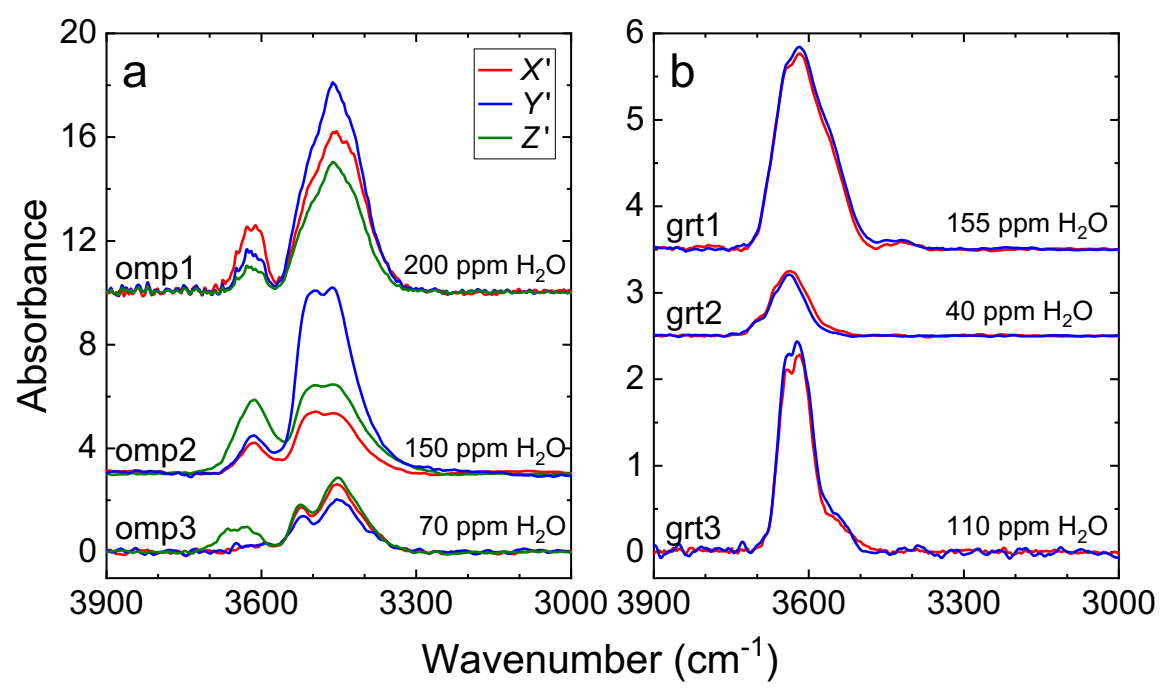


Fig. 2

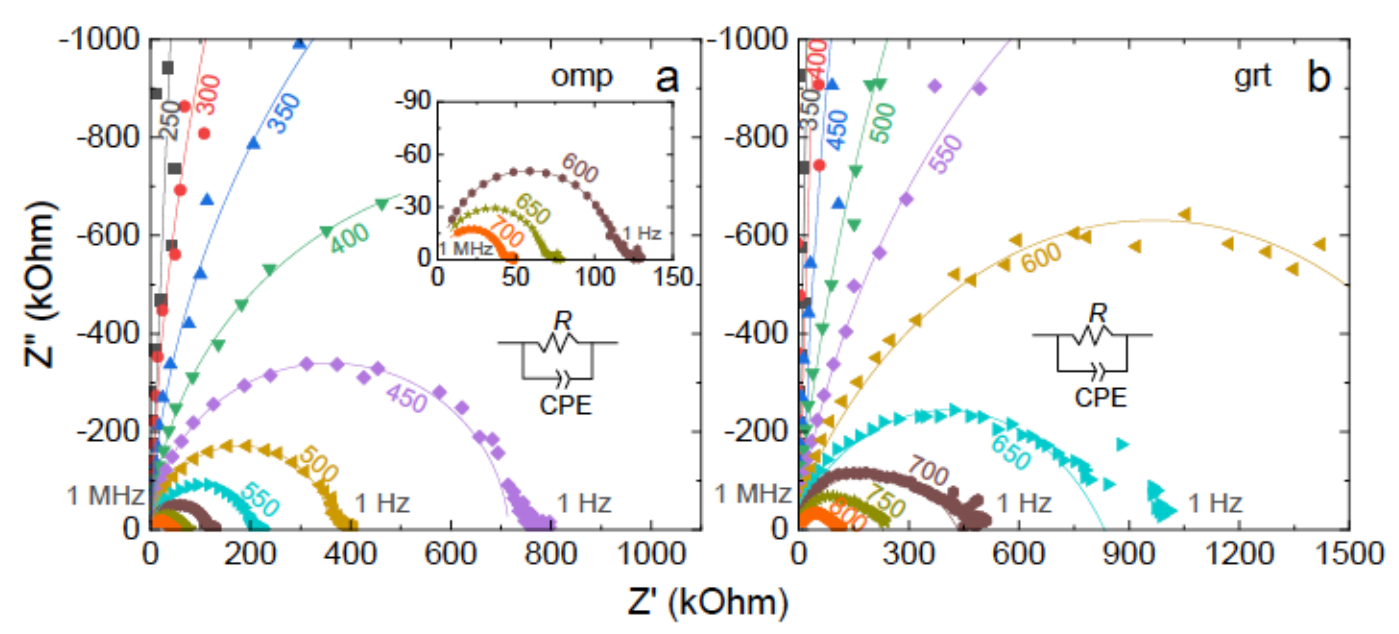

581

582

583 
Fig. 3

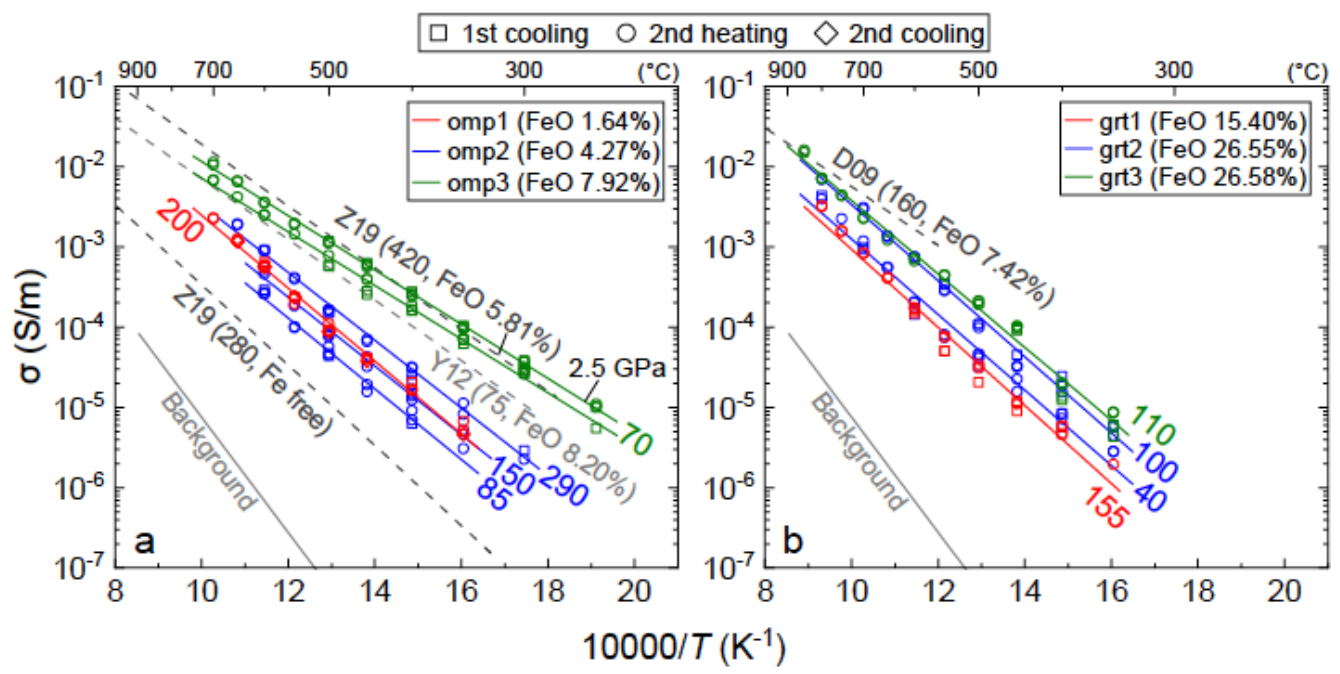

585

586 
Fig. 4

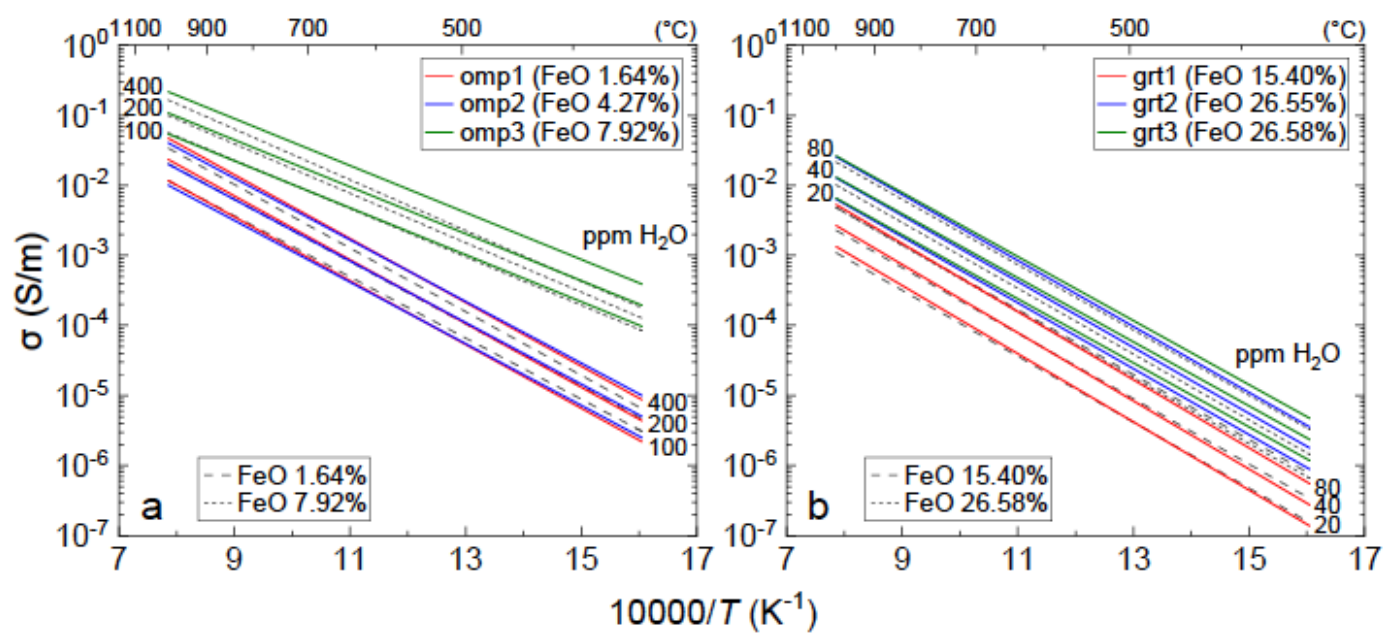

589

590

591

592 
Fig. 5
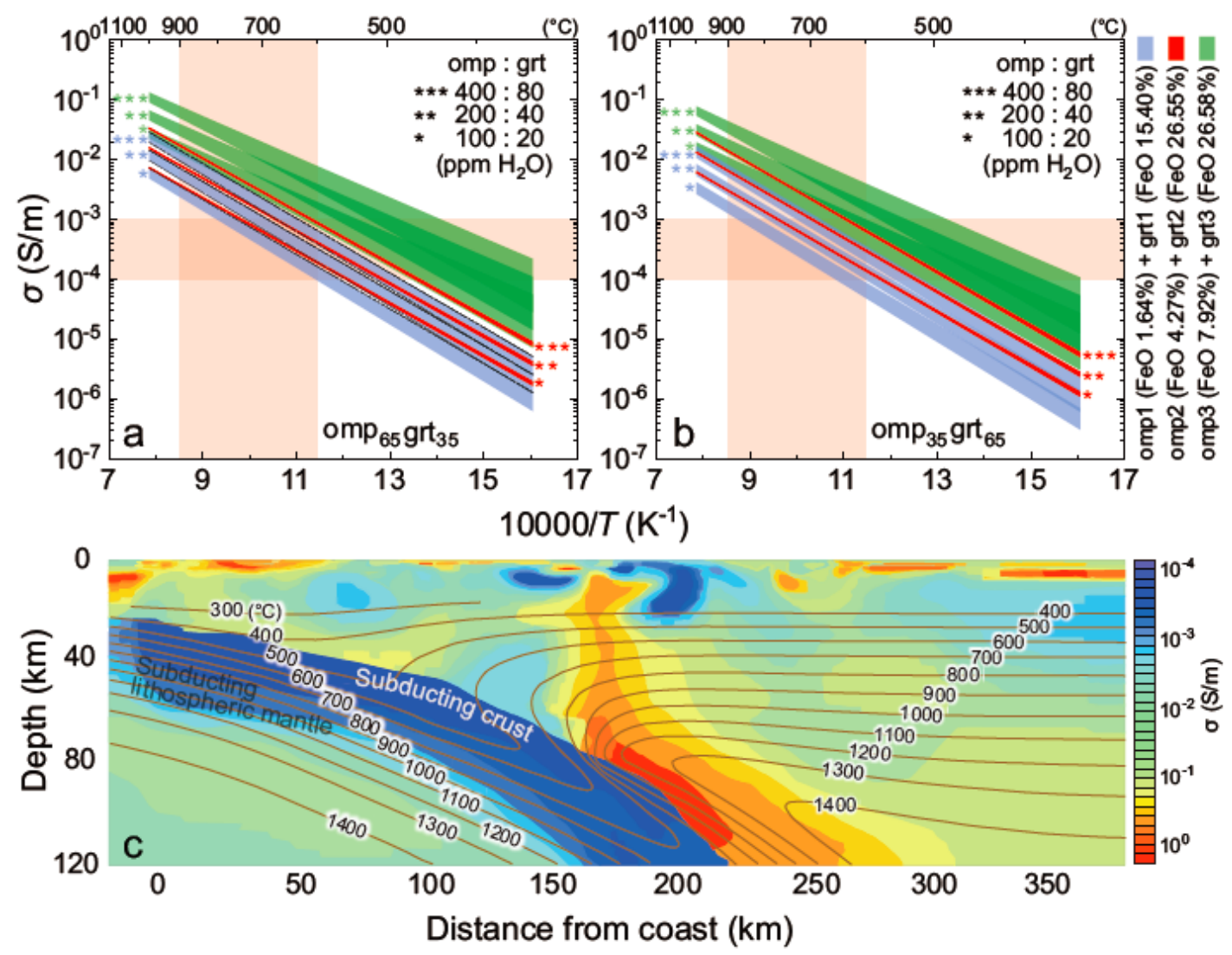

594 